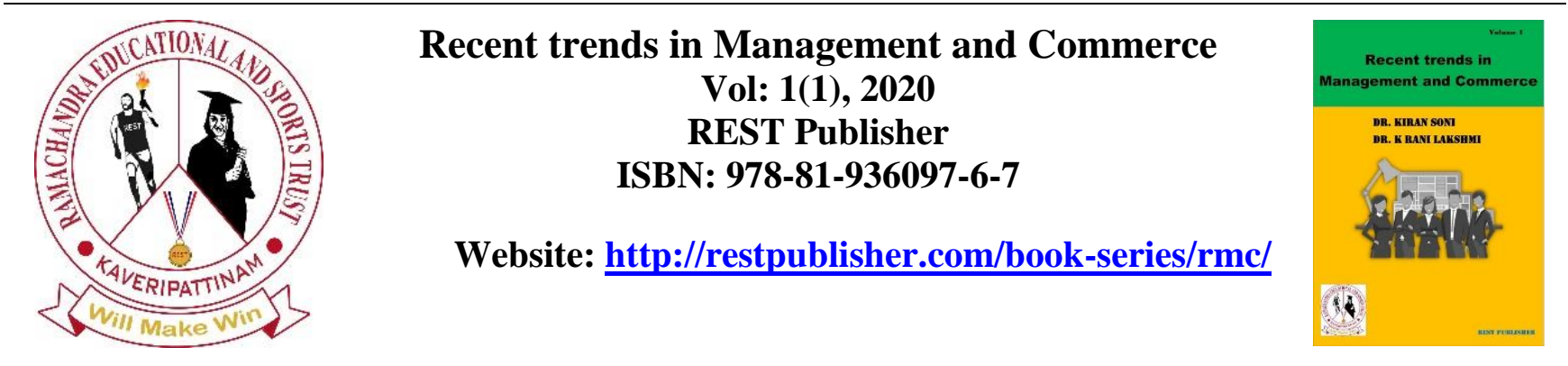

\title{
Utilization of Nursing Manpower in Medical Wards at a large teaching Hospital
}

${ }^{1}$ Ms. Asmat Parveen, ${ }^{2}$ Dr. Haroon, ${ }^{3}$ Dr. Ajaz Baba, ${ }^{4}$ Dr. Shahid Mudasir Baba, ${ }^{5}$ Ms Anjum Khurshid

1 Associate Professor cum Principal, SMMCN\&MT, Awantipora, Kashmir

2. Associate Professor, SKIMS Soura, Srinagar, Kashmir

3. Medical Superintendent in IMHANS, Govt Medical College, Srinagar, Kashmir

4. Sr.Resident, Department of Immunology, SKIMS Soura, Srinagar, Kashmir

5. Assistant Professor, Islamic University Sciences and Technology, Awantipora, Kashmir

Corresponding Author: asmat.parveen@ islamicuniversity.edu.in

The term "Nurse" Evolved from the Latin word "Nutrine" which means nourishing. Nursing has been called the oldest of the art and the longest of the profession (DONOVAN 1985) ${ }^{1}$. The roots of medicine and nursing are interrelated and found in mythology, ancient culture religion and reasoned thinking .The goal of nursing is both to help people attain, maintain retain and regain health and to help them cope with crises Illness and death. Though the history of nursing is as old as the history of mankind. The modern day nursing came into public forefront after the efforts of Florence Nightingale, who was born in May 12, 1820 at Florence in Italy. She decided to undertake nursing in response to a divine call. In those days, nursing profession was looked down upon with hatred and it had social stigma attached to it, but she preferred it in spite of all odds ${ }^{2}$. Nursing went through dark ages and enlightened periods. Nursing was primarily family based work in the part and perform all kinds of jobs like housekeeping, catering, clerical work, pottering etc. To meet the growing demands of a changing complex society, nursing evolved over the years from an exclusively family based work to a distinct health profession .There is now a worldwide trend to extend the scope of nursing practice. Nursing functions are being expanded in both developed and developing countries. Nurses need to be aware that patients and nurses often hold disparate views of the priorities of nursing care. Even when the nurses know the perceptions of patients and what satisfies them they may face certain problems which prevent them from delivering quality nursing care. Being a nurse is no bed of roses. Even in the best of organizations something may lack which prevents her from delivering quality nursing. Working in an emergency room is hectic with no periods of lulls. Every frantic minute of the day is spent racing from one task to the next. The atmosphere is even more stressful in the critical care areas. This type of work environment takes a toll on them physically, mentally and emotionally and disturbs their home environment, finally affecting the quality of their work ${ }^{3 .}$ Various studies have shown that nurses face many other problems which lead to job dissatisfaction and hence high turnover, a vicious cycle. Some of these are understaffing with huge workload, stress and burnout lack of task autonomy appreciation and recognition, inadequate salary, job stagnation etc. All these factors adversely affect quality of nursingcare. ${ }^{7}$ To meet the changing health care needs of the people, three categories of nurses are defined for the expanded role i.e,
* Nurse practitioner
* Nurse clinician and
* Nurse specialist.

Nursing services should efficiently and effectively to be utilized for better patient care. Nurses are expected to render nursing care to the patients, help the attendants of patient and his family members. Nursing in most of the Hospital render functional nursing care where as at present nursing is directed towards achieving the goal of patient centered, Family centered care using Nursing process consists of series of steps which include .

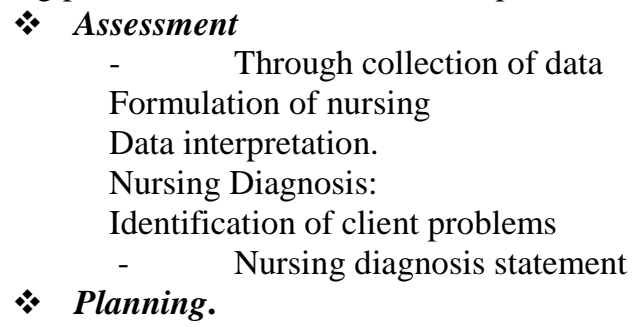




\section{* Documentation and Reporting.}

Nursing is a caring profession. From the earliest ages to the present, nurturance of human beings has been the central concern of nursing.

She provides

\section{* Direct patient care which includes.}

* Admission and discharges the patient.

* Maintenance of personnel hygiene and comforts of the patient.

* Nutritional needs of the patient

* Maintains clean and safe environment for the patients.

- Implements and maintains policies and routines

- $\quad$ Co-ordinates patient care with various health team members.

- $\quad$ Follows doctors round.

- $\quad$ Performs technical task e.g. administration of medication, assisting doctors in various medical

procedures.

Helps doctors in diagnosis and treatment

Maintenance intake and output chart

- Observes change in patient's condition records, takes necessary action and reports to the concerned authority.

Imparts health education to the patients and his family.

* Ward management role.

- Hands over and takes over the patient and ward equipment and supply.

- $\quad$ Keeps the ward neat and tidy.

- $\quad$ Maintains safety of the ward equipment

Prepares and checks ward supplies

Supervises student and other junior nursing personnel working with her.

* Educational Functions:-

- $\quad$ Participates in clinical teaching both planned and incidental.

Teaches and guides domestic staff.

Helps in the orientation of new staff.

Participates in staff education programme.

Guides student nurse.

The researcher is working in Sher-i-Kashmir institute of medical sciences so need was felt necessary to perform study on utilization and work load of nursing manpower in medical wards. So that factors affecting the utilization could be identified, which can help towards the development of nursing care plans and diagnosis and implementation $\&$ evaluation.

1. To Study the available Nursing Manpower in all Medical Wards of SKIMS.

2. To study work load and utilization of Nursing personnel in Nursing care activities.

Nurses are significant players in the provision of health care services and their actions and skill-mix affect patient outcome and length of stay. The work performed by nurses is essential to the well being of patients and clients accessing the healthcare system. Registered nurses provide the greatest hours of care and coordinate the care provided by other healthcare providers. They are the primary interface between the patient and the health care system. It is therefore essential that the work that nurses perform is understood. This requires the development of a means for identifying the specific contribution of nurses to patient outcomes as well as the resources required to affect this outcome. Currently, nurses perceive that workload exceeds current staffing levels and the capacity of nurses. Nurses are unable to complete all nursing care to the standards defined by professional regulatory bodies. The continued focus on cost and efficiency does not acknowledge the increasing complexity of care being delivered and the impact of cost-saving measures on quality of care. The negative health outcomes arising from excessive workload for the nursing community and the difficulties of retaining students and employees in nursing are compelling reasons to address the negative influence of onerous workload

Study by Isik U. Zeytinoglu etal examine associations between deteriorated external work environment, heavy workload and nurses' job satisfaction and turnover intention. Data are from our 2002 survey responses of 1,396 nurses employed in three teaching hospitals in southern Ontario. Data analyzed first for all nurses and then separately for full-time, part-time, and casual nurses. External work environment refers to nurses' perceptions of important decisions being made outside the hospital, limited resources, and budget cuts. Results show that when nurses perceive a deteriorated external work environment and consider their workload to be heavy, they also report low job satisfaction. Low job satisfaction and heavy workload, in turn, are associated with nurses' turnover intention. However, when nurses perceive a deteriorated external work environment they are more inclined to stay. When data are examined separately for each employment status group, the effect of external work environment and workload are different on turnover intentions for fulltime, part-time, and casual nurses. Study suggest managers and policymakers pay attention to the impact of deteriorated external work environment and heavy workload in developing strategies for nurses' job satisfaction and retention. More importantly, the different impact of these factors according to employment contracts should be considered in developing human resources policies for nurses' job satisfaction and retention ${ }^{6} \cdot$ Researchers from the German Institute for Quality and Efficiency in Health Care (IQWiG) gathered evidence 
on this question to see if nursing workload has been shown to have an impact on the quality of care in hospitals. They did not look at community nursing or aged care. The result of the research there is no established point to show when nurses are so overloaded that the quality of care begins to suffer. ${ }^{7}$ A study of practice nurse workload in 1989 by the East Anglian reporting system revealed that nurses were undertaking a wide range of activities, with $12 \%$ of nursing time being spent on administration. Aim of the 1989 study was repeated by the East Anglian reporting system in 1992 to investigate changes in practice nurse workload. Nurses in 22 practices recorded all the procedures they performed and their duration, over a two week period. Results indicated the number of practice nurses in each practice had increased from 0.7 full time equivalents in 1989 to 1.2 in 1992. The proportion of time spent on administration had increased to $19 \%$. The number of different procedures performed by practice nurses had risen from 36 in 1989 to 54 in 1992, with most new activity in well person and new patient clinics. The conclusion of the study indicated that changes have taken place in the volume and range of work undertaken by practice nurses. There is potential for practice nurses to use the results both for negotiation and for education ${ }^{8}$ A study by A. P. Gaudine describes 31 nurses' views of workload and work overload, identifying ten dimensions of workload and four dimensions of work overload. Findings suggest that researchers and nurse administrators do not include all of the dimensions that nurses think of when they use the word "workload". Nurse administrators who listen to nurses' experience of workload may be able to find strategies to help nurses deal with their workload. The theme of lack of control ran through the nurses' accounts of work overload. To retain nurses, employers need to allow nurses some control over their workload and some time to include in their nursing the things they enjoy the most ${ }^{9}$ A report in the Nursing Standard, published by the Royal College of Nursing stated that a survey of nearly 300000 patients by the Commission for Health and Improvement found the following:

- Three (3) in four (4) patients had confidence and trust in nurses who cared for them in hospital, but one (I) in five (5) said nurses talked in front of them as if they were not there.

- Eleven (11) thought there were never enough nurses on duty.

- A further thirty one (31) thought that there were at times, not enough nurses on duty ${ }^{10}$

Another study by Esther R. Greenglass1examines the relationship between impact of restructuring, job satisfaction, job insecurity and absenteeism in nurses. A self-report anonymous questionnaire was used to collect data. The respondents consisted of 1363 nurses employed in hospitals that were undergoing extensive restructuring. Respondents were 1,363 nurses from hospitals in communities varying in size from 50,000 to over one million people in the province of Ontario, Canada. They were primarily women (94.8\%), employed in 11 nursing units. Approximately two-thirds worked in medical/surgical, intensive care/coronary, emergency, and obstetrics units. One-half of the respondents worked part-time, working on average 31.28 hours per week $(\mathrm{SD}=10.53) .{ }^{11}$ The Academy of Canadian Executive Nurses believes nursing workload is one of the key critical issues to be addressed to ensure patient safety, retention of an adequate number of nurses for Canada and the ability of nurses in Academic Health Sciences Corporation (AHSC) centres to fulfill their mandate for care, teaching, research and innovation ${ }^{12}$. Affonso et al. (2003) identified workload as a significant issue for nurses in delivering processes of care in a way that supports patient safety. ${ }^{13}$ In today's fast-paced, complex, highly regulated healthcare environment, it is essential that patient care be administered efficiently so patient's outcomes be achieved as rapidly as possible. ${ }^{4}$ Nursing has always been directed to keep people healthy and provide comforts, care and assurance to ill. Nursing care refers to care o others. The care may involve any number of activities ranging from carrying out complicated technical procedures to something as simple as holding a handle. The central focus of nursing care and included the physical, emotional, social and spiritual dimensions of that persons. ${ }^{5}$ To study available manpower working in ten earmarked medical wards in SKIMS, a prospective study from 15 July was undertaken utilizing a mixed methodology .Study of available records in nursing administration and interviews s with the concerned authorities' were undertaken with the aim of elucidating the nursing manpower in said wards. In addition to study of manpower, the organization and layout of nursing administration was also studied. To study work load of nursing personnel in three medical wards of Sheri Kashmir institute of medical sciences direct observational study was performed from 15 th July 2007 to 30th august 2007 for a period of 45 days. The medical wards earmarked for the study were Cardiology, Gastroenterology and general medicine. For the study a Performa was designed (Annexure 1) which in addition to demographic profile of the study subject covered various aspects of nursing workload,. The workload of nursing was broadly divided into three broad categories:

$$
\begin{array}{ll}
\circ & \text { Direct patient care activities. } \\
\circ & \text { Indirect patient care activities. } \\
\circ & \text { Personnel Activities }
\end{array}
$$

A pilot study was done on 30 nursing personnel to see the reliability of the tool. For the study the researcher visited the wards during day and evening night and Sundays and observed the working of various cadres of nursing personnel. The observation of each personnel was recorded on pre-designed proforma along with their demographic profile. 30 nursing personnel were observed for different duty hours during the period of the study. They included:

15 nursing staffs for morning duty.

6 nursing staffs for evening-night.

4 Nursing supervisors for general shift.

5 ward in charges for general shift.

Different patient care activities as per the questionnaire (Performa) were studied by the researcher in the earmarked wards and time spent (minutes) in each activity were entered on the Performa. Timings spent on three broad categories of activities i.e. direct, indirect and personnel were summated and analyzed. Ward is a place where a group of patients are treated for different diseases and cared for sickness. Wards are also utilized for the purpose of research in medical and nursing fields and training of medical, nursing and paramedical personnel. Sher-i-Kashmir Institute of Medical Sciences is a 600 bedded teaching hospital commissioned during Dec.1982. Besides teaching and research activities Sher-i-Kashmir Institute of Medical Sciences has been imparting quality patient care in various branches of medicine including super-specialties like cardiothoracic surgery, Neuro surgery, Urology, Paediatric surgery, plastic Surgery, Gastrointestinal surgery. Some 
sophisticated and advanced surgeries are being conducted at this hospital. The system of nursing followed in Sher-i-Kashmir Institute of Medical Sciences is primary nursing where an in charge is responsible for ward activities round the clock.

To study the Manpower organizational layout

Manpower is one of the essential pillars of management and nursing manpower of a hospital is key to the delivery of efficient and effective patient care.

Nursing manpower was studied and observation regarding the same are tabulated below:

Table-1:Nursing Manpower in Ten (10) Medical ward

\begin{tabular}{|c|l|c|}
\hline $\begin{array}{c}\text { S. } \\
\text { No }\end{array}$ & \multicolumn{1}{|c|}{ Staff Cadre } & Strength \\
\hline 1 & Nursing Supervisors & 12 \\
\hline 2 & Ward in charges & 18 \\
\hline 3 & Staff Nurses & 53 \\
\hline 4 & Nursing Aids & 54 \\
\hline
\end{tabular}

Study was observed in three medical wards viz Cardiology, Gastroenterology and General Medicine. Each ward has one supervise, two incharges i.e incharge 1 and in charge 2 and nursing staff for shift duties. Supervisors do general shift i.e. $10 \mathrm{o} 4 \mathrm{pm}$ and other nursing staff do round the clock. Junior nurses are assigned to 10 patients during day shift for nursing care.

Physical layouts of nursing units in medical ward was studied. The layout diagram is given below

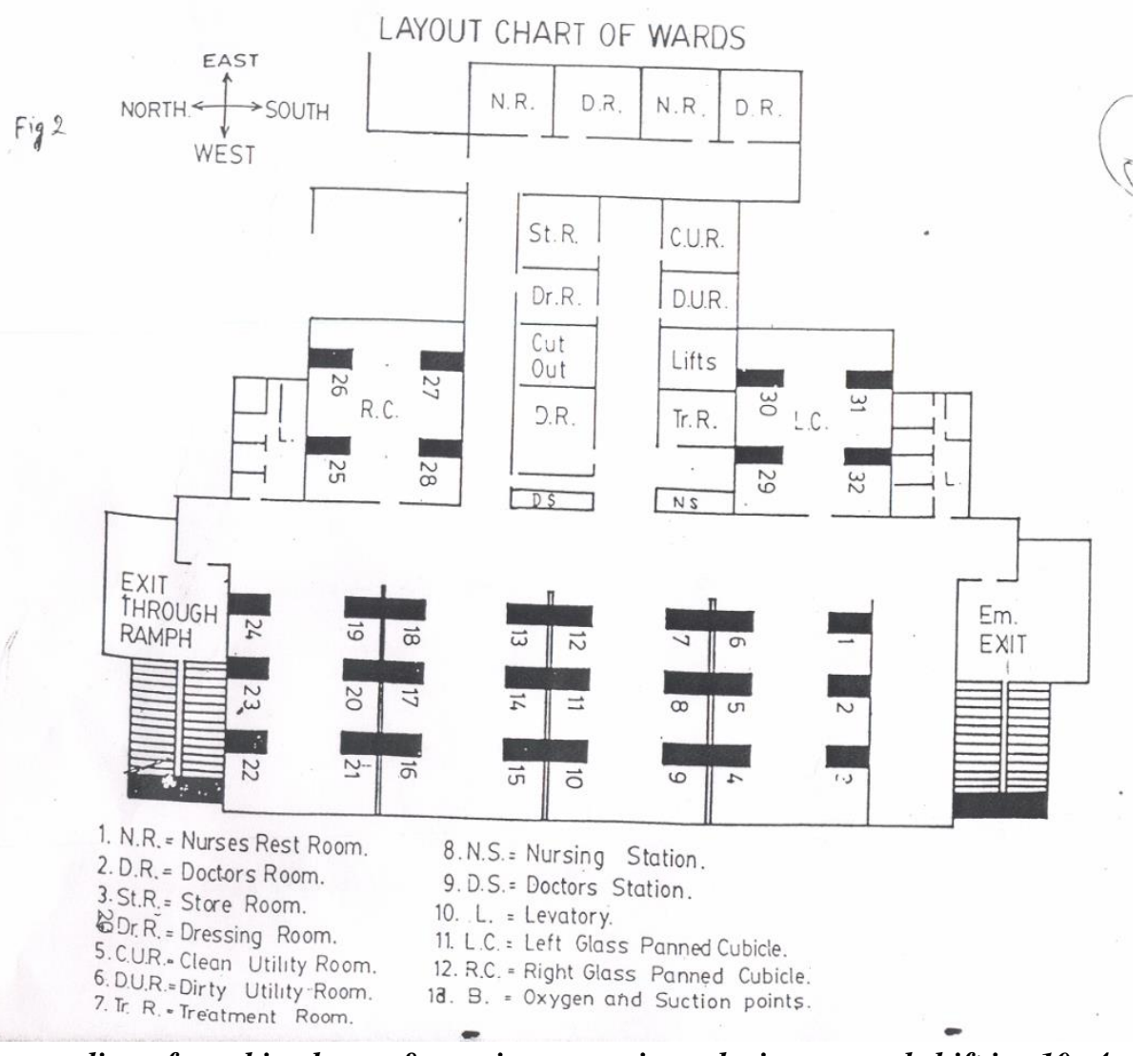

Activity sampling of ward in charge \& nursing supervisors during general shift i.e. 10 -4 pm

Observations for the same were recorded under three broad headings.

- $\quad$ Direct Patient care activity.

- Indirect patient care activity.

- Personnel activity

Observations for direct patient care activity of ward in charge \& nursing supervisors revealed that most of the time was utilized for:

$>$ Attending round with doctor's i.e. $120 \mathrm{mts}$ which is mean spent time for these activities.

$>$ Interacting with patients (10 mts), (18 mts).

$>$ Administration of drugs (20mts).

Indirect patient care activity most of the time was spent on.

$>$ Making admission of patient i.e (20 mts) $(16 \mathrm{mts})$

$>$ Discharge of patient (40 mts), (10 mts).

$>$ Making of registers (22.5), (10 mts).

$>$ For any other indirect activity (10 mts), (11 mts).

For personnel activity meantime spent was around $60 \mathrm{mts}$ which includes lunch \& prayers etc.

Activity sampling of staff nurses for evening + night duty (18 hrs) 
Observation for Direct patient care activity in case of staff nurses for evening + night duty revealed that most of the time was utilized for

$>$ Administration of drugs to patient i.e.(150 mts) (mean time spent).

$>$ Distribution of drugs (70 mts)

$>$ Monitor vital signs (60 mts)

$>$ Attending round with doctors (46.66 mts).

$>$ Preparing Patient for procedures (45 $\mathrm{mts})$.

$>$ Interacting with patient (35 mts)

Observations for Indirect patient care activity revealed that most of the time was utilized for

$>$ Any indirect activity $(260 \mathrm{mts})$.

$>$ Attending phone calls (28.33 mts).

$>$ Checking of inventories \& equipment (26.88 mts).

$>$ Making nurses notes of patient (23.33 mts).

$>$ Personnel activity (60 mts).

Activity sampling of staff nurses for morning duty i.e. 10 to $4 \mathrm{pm}$.

Direct patient care activity observed revealed that most of the time was spent on:-

$>$ Administration of drugs to patient (42 mts).

$>$ Attending round with doctors (34 mts).

$>$ Monitoring vital signs (28 mts).

$>$ Distribution of drugs to patient (18 mts).

$>$ Preparing patient for procedures $(20 \mathrm{mts})$.

Indirect patient care activity revealed that most of the time utilized for:-

$>$ Making admission of patient (10 mts).

$>$ Making discharge of patient (6.66 mts).

$>$ Attending phone calls (14.66 mts)

\section{Personnel Activity}

Most of the time spent for this activity is around $50 \mathrm{mts}$ which includes lunch and prayer etc.

Comparative analysis of activity sampling (Table 2) (Fig 1) of the study subjects revealed that Staff nurses spend most of their time in delivering direct patient care activities (i.e. $206 \mathrm{mts}$ ) in comparison to nursing supervisors and ward in charges (140 mts \& $134 \mathrm{mts}$ respectively).Nursing supervisors and nursing in charges use most of their time (150 mts \& $146 \mathrm{mts}$ respectively) in indirect patient care activities.

Table-2: Comparison of Activity sampling of Nursing Supervisors, Nursing Incharges and Staff Nurses.

\begin{tabular}{|c|c|c|c|}
\hline \multirow{2}{*}{ Activity } & \multicolumn{3}{|c|}{ Time Spent (General Shift) 6 hours duty } \\
\cline { 2 - 4 } & $\begin{array}{l}\text { Nursing } \\
\text { Supervisors }\end{array}$ & $\begin{array}{c}\text { Nursing } \\
\text { Incharge }\end{array}$ & Staff Nurses \\
\hline $\begin{array}{c}\text { Direct } \\
\text { Activity }\end{array}$ & 140 & 134 & 206.98 \\
\hline $\begin{array}{c}\text { Indirect } \\
\text { Activity }\end{array}$ & 150 & 146 & 98.02 \\
\hline $\begin{array}{c}\text { Personal } \\
\text { Activity }\end{array}$ & 70 & 80 & 55 \\
\hline
\end{tabular}

Fig1:

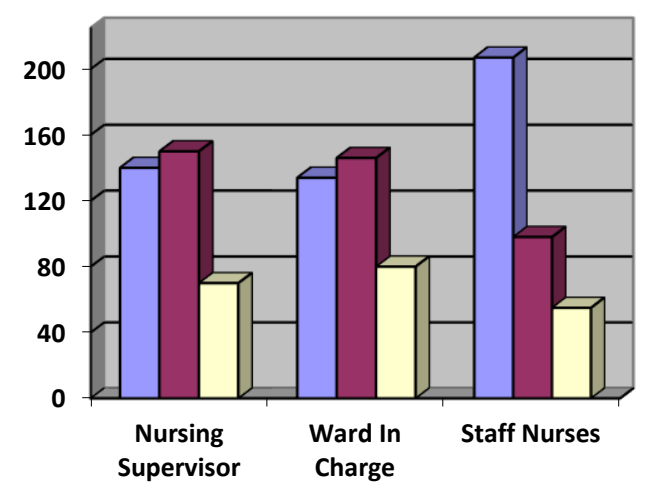

口Direct Activity Q Indirect Activity aPersonnel

Analysis of the data for comparison of activity sampling for evening night and day shift duty of staff nurses(Table 3 Fig 2) revealed that they spend $506 \mathrm{mts}$ in delivering direct patient care activities during evening night shift against $206 \mathrm{mts}$ spend during day shift. Staff nurses utilize about $435 \mathrm{mts}$ for direct patient care activities in comparison to $98 \mathrm{mts}$ for day shift.

Table 3: Comparison of activity sampling for Evening night and Day shift duty of staff nurses 
Asmat. et.al / Recent trends in Management and Commerce Vol: 1(1), 2020: 67-73

\begin{tabular}{|c|c|c|}
\hline Activity & $\begin{array}{c}\text { Nursing staff Evening } \\
+ \text { night }\end{array}$ & $\begin{array}{l}\text { Nursing staff } \\
\text { Morning shift }\end{array}$ \\
\hline Direct Activity & 506.64 & 206.98 \\
\hline Indirect Activity & 435.8 & 98.02 \\
\hline Personnel Activity & 137.56 & 55 \\
\hline
\end{tabular}

Fig.2:

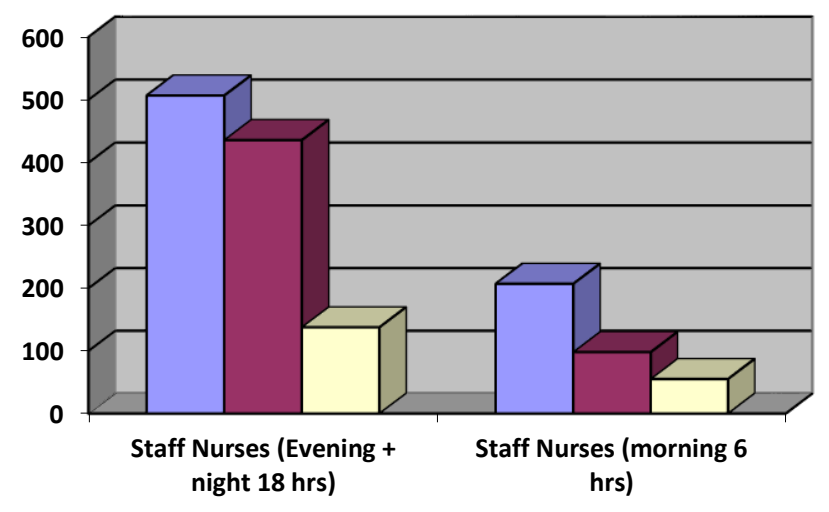

口Direct Activity alndirect Activity aPersonnel Activity

In today's fast paced complex, highly regulated healthcare environment, it is essential that patient care be administered efficiently so patient s outcomes can be achieved as rapidly as possible. ${ }^{18}$ Nursing has always been directed to keep people healthy and provide comfort, care and assurance to the ill. Nursing care refers to the care of others .The care may involve any number of activities ranging from carrying out complicated technical procedures to something as simple as holding handle. The central focus of nursing care is the person relieving care and include the physical, emotional, social and spiritual dimensions of that person. ${ }^{19}$ Nursing manpower was studied and observation regarding the same revealed that the staff of the ten medical wards was constituted by 12 Nursing supervisors, 18 ward in charges 53 staff nurses and 54 nursing aids. Supervisors do general shift i.e. 10 to $4 \mathrm{pm}$ and other nursing staff do round the clock. Junior nurses are assigned to 10 patients during day shift for nursing care. The organizational structure of nursing at SKIMS identified Medical superintendent as the operational head followed by Nursing superintendent, Deputy nursing superintends, Assistant nursing superintend, Staff nurses and nursing aids in the line of command. Trained Nurses Association of India and Indian Nursing council suggests one nursing Superintend for 400 hospitals beds and one Assistant Nursing superintend for 100 - 150 beds. The council also suggests one staff sister for 3 beds in a teaching hospital in general wards. ${ }^{\mathbf{1 4}}$ Observations for Activity sampling of ward in charge, nursing supervisors and staff nurses were recorded were recorded under three broad headings.

- $\quad$ Direct Patient care activity.

- Indirect patient care activity.

- Personnel activity

The study revealed that Nursing supervisors spend $150 \mathrm{mts}$ in indirect patient care activities, $140 \mathrm{mts}$ in Direct and $70 \mathrm{mts}$ on personal activities. Nursing In charges spend 146mts in delivering indirect patient care activities. Observations for direct patient care activity of ward in charge \& nursing supervisors revealed that most of the time was utilized for attending round with doctor's (120 mts).Indirect patient care activity performed by Nursing supervisors and Nursing Incharges revealed that most of the time was spent on making admission of patient i.e. (20 mts) (16 mts) and making discharges of patient (40 mts), (10 mts).Study conducted by the National Institute of Health and Family Welfare showed that only $56.7 \%$ of all the nursing activities were patient centered, of which $31.3 \%$ were in direct patient care. ${ }^{15}$ Academy of Hospital Administration recommends $3-5$ hours of nursing care for moderately ill patients with a nursing patient ratio 1:3.For chronically ill patients the Academy suggests $30 \mathrm{mts}$ to $1 \mathrm{hrs}$ of nursing care ${ }^{16}$. Staff nurses during their 6 hour shift duty spend $206 \mathrm{mts}$ in direct patient care activities in comparison to $98 \mathrm{mts}$ spend in delivering indirect patient care activities .For Direct patient care activity most of the time was spent on administration of drugs to patient (42 mts),Monitoring vital signs (28 mts), Distribution of drugs to patient (18 mts),Preparing patient for procedures $(20 \mathrm{mts})$.In a study carried out by the National Institute of Health and Family Welfare in the medical and surgical wards of a general hospital ,the results showed that the average time taken per patient in different shifts varied from $196 \mathrm{mts}$ to $10 \mathrm{mts}$ for different degrees of dependencies. The study revealed that for morning shift duty in partially dependent and fully ambulant patient varied from $97 \mathrm{mts}$ to $72 \mathrm{mts}{ }^{15}$. Comparison of the activities of the cadres of study that Staff nurses spend most of their time in delivering direct patient care activities (i.e. 206 $\mathrm{mts}$ ) in comparison to nursing supervisors and ward in charges (140 mts \& $134 \mathrm{mts}$ respectively). Shanks et al in their study established that staff nurses averaged $41 \%$ of time in direct patient care activities, with 25 to $30 \%$ of the remainder in planning and coordination of care and in communication. The head nurse spent only $15 \%$ of her time and the nurse supervisor $7 \%$ in direct patient care.${ }^{17}$ Comparison of various activities performed by nursing staff during evening night and day shift duty revealed that staff nurses spend $506 \mathrm{mts}$ in delivering direct patient care activities during evening night shift against 206 mts spend during day shift. Staff nurses utilize about $435 \mathrm{mts}$ for direct patient care activities in comparison to $98 \mathrm{mts}$ for day shift. Study by National Institute of Health and Family Welfare reveals that Patient centered activities accounted for 
$42.9 \%$ in the morning $41.6 \%$ in the evening and $23.6 \%$ in the night shift.${ }^{15}$ Nursing has been called the oldest of the art and the longest of the profession. The roots of medicine and nursing are interrelated and found in mythology, ancient culture religion and reasoned thinking. The goal of nursing is both to help people attain, maintain retain and regain health and to help them cope with crises Illness and death. They are the primary interface between the patient and the health care system. It is therefore essential that the work that nurses perform is understood. This requires the development of a means for identifying the specific contribution of nurses to patient outcomes as well as the resources required to affect this outcome. With this background the study "Utilization of Nursing Manpower in Medical wards at SKIMS was undertaken with the prime objective of studying the available manpower of nursing personnel working in medical wards at SKIMS and in addition to study their work load and utilization. To study available manpower working in ten earmarked medical wards in SKIMS, a prospective study from 15 July was undertaken utilizing a mixed methodology. For studying work load of nursing personnel in three medical wards of Sheri Kashmir institute of medical sciences direct observational study was performed from $15^{\text {th }}$ July 2007 to $30^{\text {th }}$ august 2007 for a period of 45 days. The medical wards earmarked for the study were Cardiology, Gastroenterology and general medicine. The workload of nursing was broadly divided into three broad categories:

* Direct patient care activities.

* Indirect patient care activities .

* Personnel Activities

Manpower is one of the essential pillars of management and nursing manpower of a hospital is key to the delivery of efficient and effective patient care. Nursing manpower was studied and observation revealed that the staff of the ten medical wards was constituted by 12 Nursing supervisors, 18 ward in charges 53 staff nurses and 54 nursing aids which are in consonance with the norms set by Academy of Hospital Administration. The organizational structure of Nursing at SKIMS identified Medical superintendent as the operational head followed by Nursing superintendent, Deputy nursing superintends, Assistant nursing superintend, Staff nurses and nursing aids in the line of command which are in agreement with the norms set by the Indian Nursing Council . Nursing supervisors on an average spend $150 \mathrm{mts}$ in indirect patient care activities, $140 \mathrm{mts}$ in Direct and $70 \mathrm{mts}$ per day on personal activities. Nursing In charges spend 146mts in delivering indirect patient care activities per day on an average. Staff nurses during their 6 hour shift duty spend $206 \mathrm{mts}$ in direct patient care activities in comparison to $98 \mathrm{mts}$ spend in delivering indirect patient care activities. Nursing staff during evening night and day shift duty revealed that staff nurses spend $506 \mathrm{mts}$ in delivering direct patient care activities during evening night shift against $206 \mathrm{mts}$ spend during day shift. The study in conclusion highlights organizational structure as well as nursing manpower at SKIMS .In addition the study highlights the work load of various cadres of nursing viz a viz Direct and Indirect patient care activities.

\section{References}

01 Dr Waqar-Ul-Nissa et al. " Nurse and the ICU " souvenir of continuing educational program on latest trends in surgical nursing" Aug 2003 page 3-4.

02 Dr. Ab Majeed "International Nursing Day 12 th may “ Journal of Nursing practice and research " July 2006 Vol 5 No 2x1 page 9-13.

03 John Sweeny et al. "Development of the Irish patient perception of Quality of care survey : International Journal of quality in Health care 15:163-168 (2003).

04 Basavanthapa BT. Nursing administration Ist ed. Jaypee. New-Delhi 2000.

05 Taylor C et al. Fundamentals of Nursing $3^{\text {rd }}$ Edition lippirocott, 1977.

06 Isik-u Zeytinoglic et al “ Deteriorated External work Environment, Heavy work load and Nurses job satisfaction and turnover intention" Canadian Public policy journal Vol 33 : 31-48 Jan 2007.

07 Nursing cologne: IQWIG. "Association between nursing capacity and quality of outcome in inpatient care August 2006

08 A Hibble " Practice Nurse workload before and after the introduction of the 1990 contract for general practitioner" Br. J.Gen Practice 1995-Jan : 45(390): 35-37

09 A.P Gaudine "What do nurses mean by work load and work overload?" Nursing Leadership (CJNL) 13(2) 2000: $22-27$.

10 Report of Nursing standards Royal collage of Nursing commission for health Denosa.

11 Esther R et al. impact of Restructuring job. Insecurity and job satisfaction in hospital nurses stress news January 2002 vol 14-no1

12 Mary Farguson Pane et al. Acen position statement nursing workload. A priority for health care nursing leadership Etnl 1792- 2004:24-26.

13 Affonso, D.D et al. " Patient safety to frame and reconcile nursing issues" Canadian journal of nursing leadership 16(4) : 69-81.

14 Dr. S.B Arora et al. "Ward management and nursing care” clinic diagnostic and therapeutic services PGDHHM Vol 04 Unit $3 ; 31 ; 39$.

15 B.M Sakharkar et al. "Nursing Services" Principals of Hospital Administration and planning 1998 Jaypee Pub. Chapter 5 pp 85-94.

16 Academy of Hospital Administration, Diploma in Hospital and Health Administration course paper II, $11^{\text {th }}$ edition 2000.

17 Shanks, Mary D Kennedy A: Administration in nursing McGraw Hill Book Co. New York, 1990. 